\author{
Military Technical College \\ Kobry El-Kobbah, \\ Cairo, Egypt.
}

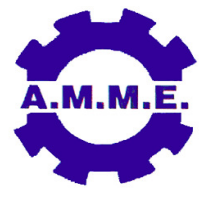

\title{
NUMERICAL STUDY ON THE EFFECT OF SECONDARY AIR INLET CONDITIONS ON A GAS TURBINE COMBUSTOR BURNING NATURAL GAS
}

\author{
A. E. Zaid , A.I. Farag ${ }^{* *}$ and T.M. Belal ${ }^{* *}$
}

\begin{abstract}
The present work numerically investigates the effect of secondary air conditions on the combustion of natural gas/air mixture in a gas turbine combustor. Secondary air is introduced normally at the combustor first half. Secondary air test conditions include its flow rate, entry position, and its arrangement around the combustor periphery and the total number of inlet ports. Secondary air inlet ports are located at different levels along the combustor length. Each level includes a number of inlet ports uniformly distributed around the combustor periphery. The number of ports levels varied from four to sixteen and the number of ports in each level varied from four to sixteen ports. Thus, the total number of ports varied from 16 up to 256 . The primary air swirl number is kept constant during tests taking the value of 0.87 . A three dimensional (SST k-omega) model is used to simulate the turbulent isothermal flow and the non-premixed combustion model was used to simulate the turbulent reacting flow using a CFD package Fluent 12. For validation of the models used, a comparison between the calculated axial temperature distributions with the measured results of other investigators was made and showed a satisfactory agreement. Secondary air showed a remarkable effect on temperature distribution inside the combustor. For secondary to primary air mass ratio (SPAR) above 0.3 , the flame becomes wider in diameter and longer in length when SPAR is increased. The NO increases by about $58 \%$ and $12 \%$ when the SPAR increases from 0 to $90 \%$ for the ports arrangement of $4 \times 4$.
\end{abstract}

\section{KEY WORDS}

Natural gas combustion, Pollutant emissions, primary air, secondary air, swirl number and CFD.

\footnotetext{
* AASTMT. Alexandria, Egypt. E-mail: akramz22@hotmail.com

** Lecturer Free, Alexandria, Egypt. E-mail: enfarag1611@yahoo.com

*** Faculty of Engineering, Pharos University, Alexandria, Egypt. E-mail:

Tarek.Belal@pua.edu.eg
} 


\section{NOMENCLATURE}

\begin{tabular}{|c|c|c|c|}
\hline $\begin{array}{l}\mathrm{PA} / \mathrm{F} \\
\mathrm{S} \\
\mathrm{L} \\
\mathrm{L}_{f} \\
\text { SPAR }\end{array}$ & $\begin{array}{l}\text { Primary air to fuel mass ratio } \\
\text { Primary air swirl number } \\
\text { Combustor length } \\
\text { Flame length } \\
\text { Secondary to primary air } \\
\text { mass ratio }\end{array}$ & $\begin{array}{l}\text { RFZ } \\
r / R \\
X / D \\
\Phi\end{array}$ & $\begin{array}{l}\text { Reversed flow zone } \\
\text { Dimensionless radial distance. } \\
\text { Dimensionless axial distance. } \\
\text { Equivalence ratio }\end{array}$ \\
\hline
\end{tabular}

\section{INTRODUCTION}

Air entering a gas turbine combustor is divided into two streams, primary and secondary air. Primary air is characterized by swirl number, inlet temperature and air to fuel ratio $(A / F)$. Secondary air may be characterized by its amount relative to the primary air (SPAR), its inlet locations, and distribution [1, 2]. Studies [3, 4] showed that the swirl number above 0.6 and $A / F$ ratio above 30 are convenient for achieving suitable flame size by which the effect of secondary air on flame is obvious. A part of secondary air is used in combustion and the rest is used for cooling the combustor walls and is used for flame dilution or the control of the exit flame temperature that affects the gas turbine blades. One of the advantages of introducing the secondary air is to improve flame stability, minimize flame size, which leads to minimize the combustor size and reducing the exhaust species $[5,6]$.

Thus, secondary air has been a critical parameter that affects combustion in a gas turbine combustor. This effect of secondary air depends also on its inlet location and the arrangement of the inlet ports along the combustor [7]. Combustion characteristics in gas turbine combustors include uniform temperature distribution of the flame especially at the combustor exit and combustion exhaust emissions. Parameters such as swirl number, A/F ratio and combustor geometry affect the flow aerodynamics, temperature distributions inside the combustor and therefore the combustion characteristics, exhaust emissions and species concentrations have been extensively studied [8-13].

Gad et al. [5] studied experimentally the effect of secondary air on Kerosene spray combustion characteristics. Results show that flame stability is improved by increasing the air swirl number and secondary to primary air ratio using the secondary air in normal direction. The reversed flow zone (RFZ) size is decreased by increasing the secondary to primary air ratio. Increasing air swirl number and secondary air to primary air ratio leads to a decrease in the flame size, an increase in the flame temperature and the size of the high temperature region inside the flame. Increasing the secondary to primary air ratio leads to a decrease in $\mathrm{CO}$ and $\mathrm{NO}_{\mathrm{x}}$ concentrations and an increase in $\mathrm{CO}_{2}$ concentration.

Gad et al. [9] also investigated experimentally the effect of secondary air direction on Kerosene spray combustion characteristics. Secondary air was used in four directions; normal, forward, backward and tangential direction. The results show that flame stability improves by increasing the secondary air amount with normal, forward 
and tangential directions and decreases at backward direction. They reported that tangential secondary air gives the shortest flame length.

Abdel-Samed [14] studied the flame characteristics and emissions of natural gas in a water-cooled tubular combustor. The combustor was designed to study flame stability, flame characteristics and exhaust emissions of Natural Gas flame. operational conditions of the burners has greater effects than changing the swirl number. The overall heat flux of outer fuel supply was much greater than those of central fuel supply, for the same swirl number.

Lebedev et al. [15] studied the flow field inside a gas turbine combustor using a three-dimensional CFD simulation. The objective was to predict the emissions characteristics inside the combustor burning methane and aviation kerosene fuels. Primary air entered as outer swirled co-flows. Secondary air was supplied at about $40 \%$ of the air flow. The combustor model was validated against experimental $\mathrm{NO}_{x}$ emissions and a reasonable agreement was obtained.

A computational study was performed by Mare et al. [16] to predict the temperature and species concentrations in a swirl non-premixed combustion using propane. The combustor is located inside a large duct of "plenum fed". The conditions at the primary jet, swirl, and fuel flow play a major role on turbulence structure.

Zhang et al. [17] performed an experimental investigation of the turbulent reacting flow in a swirl combustor. Air injected into the combustor composed of primary swirling jet and the secondary non swirling jet. A three dimension-laser particle dynamic analyzer was employed to measure the instantaneous gas velocity. The probability density functions (PDF) for the instantaneous gas axial and tangential velocities at each measuring location are obtained. The measured results delineate the turbulence properties of the swirling reacting flow under the condition of staged combustion.

Shehata M. [18] studied experimentally the formation of $\mathrm{O}_{2}, \mathrm{CO}, \mathrm{CO}_{2}$, flame and wall temperatures in a premixed gas turbine combustor. Primary/secondary air ratios varied during the experiments. Increasing the secondary air ratio leads to a decrease in the wall temperatures. The inner liner wall temperatures are more affected by varying the primary air ratio while the outer liner wall temperatures are more affected by varying the secondary air ratio.

From the above literature review, it is shown that most investigations included the effect of air swirl and the effect of primary air with little focus on the effect of secondary air in gas turbine combustor. There is not enough data about the effect of the secondary air inlet conditions on the combustion characteristics in a gas turbine combustor. Therefore, the present paper is concerned with the numerically study of the effect of secondary air amount, inlet position, the numbers and arrangement of secondary air ports along the combustor on natural gas combustion. The investigations are performed for constant swirl number and A/F ratio. 


\section{CFD SIMULATIONS}

The combustion of gaseous fuels in gas turbine combustors is highly complex. It includes hot gas recirculation, energy exchange and strong turbulence-chemistry interactions. Therefore, the computational fluid dynamics (CFD) represents an economic and reliable tool for facilitating the combustion system design. CFD gives the power to simulate flows, heat and mass transfer and chemical reactions. This provides data which help in predicting the performance of designed model. In the present study, turbulent reacting flow is simulated using the CFD package fluent 12 .

\section{Mesh Construction}

For the present study, model geometries and meshes are generated using Gambit program 2.3. Meshes of tetrahedral cells are created having different cell sizes according to the regions of importance in the computational domain. Regions of interest are those between swirl vanes, near the walls and at secondary air inlets. Fig. 1 shows the solid geometry and the computational mesh of the combustor model constructed with air swirl of swirl vane angles of 45 degree. Solution accuracy can be improved by careful distribution of the grid nodes which offers a good compromise between the computational time and the numerical accuracy.

The mesh constructed without using secondary air represents the base combustor model. Other model meshes represent different conditions of secondary air inlets. Based on previous experimental data boundary conditions were specified for fuel and primary air mass flow rates and inlet velocities for secondary air. Tetrahedral mesh type is used in this study. A steady state pressure based solver is used to solve the governing equations and the node-based for gradient option is selected which is suitable for tetrahedral meshes. Also, the pressure based solver is used with presto scheme is recommended as discretization method for solving pressure in this case. For turbulence modeling, the shear-stress transport (SST) $k-\omega$ model in fluent 12 is preferred because of its better agreement with the experimental data of Ref. [22]. The non-premixed combustion model was selected for modeling the reacting flow. The $\mathrm{P} 1$ radiation model is also selected.

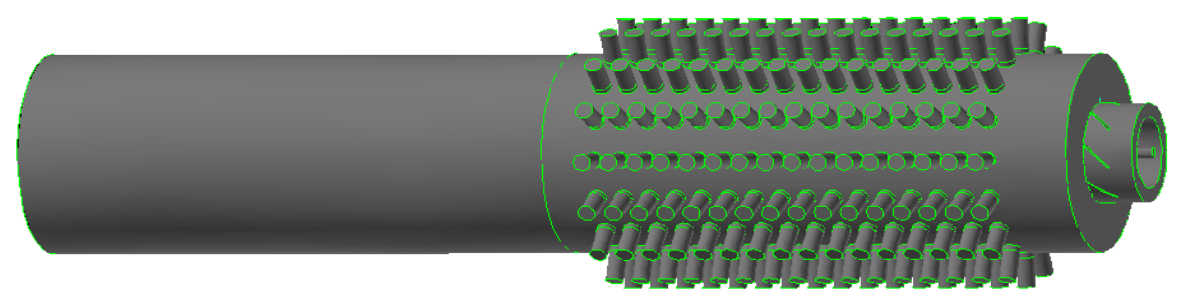

Fig.1-a. The combustor model geometry with 16-16 ports.

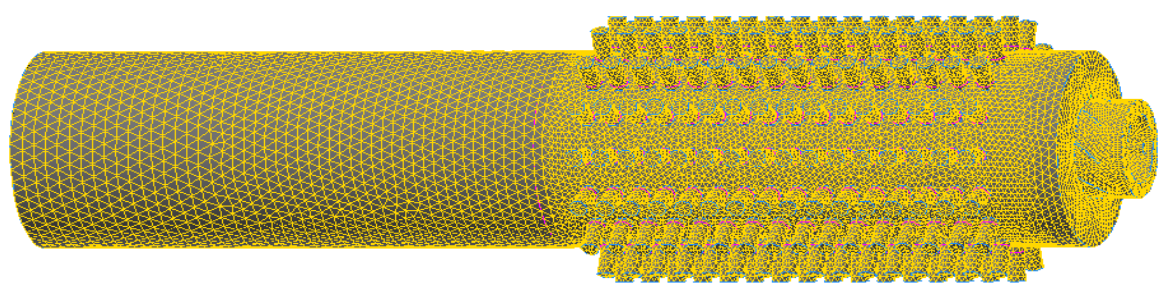

Fig.1-b. Computational grid of $16 \times 16$ ports [Swirl Number of 0.87 ]. 


\section{Numerical Procedures}

The numerical procedures used in the present investigation can be summarized as follows:

- Creating the model geometry and meshing using Gambit program 2.3.

- Importing the model mesh to FLUENT solver.

- Selecting the appropriate solver formulations.

- Choosing the physical models to be solved

- Specifying the material properties.

- Specifying the boundary conditions for fuel inlet, primary air inlet, secondary air inlets, the fluid interior and the combustor walls.

- Calculating the solution: Solving the continuity, momentum and $k-\varepsilon$ turbulence equation using the appropriate algorithms.

- SIMPLE algorithm (pressure-predictor-correction method)

- Obtain the velocity, pressure and turbulence distribution

- Solve the energy equation and calculate the temperature distribution

- Calculate the species production using the eddy-dissipation model

- Transfer the species production to the source terms of the species transport

- State the Governing Equations inside the solvers.

\section{Grid-Independency Study}

A grid independence test has been performed, considering the computational expense and time, with cell numbers of 100000, 150000, 20000, 250000, 300000, 350000 and 400000 cells. Solutions of centerline axial velocities are performed for meshes with different cell sizes. There is a satisfactory agreement of axial velocity for 200000, 250000 and 300000 cells meshes while others are far. Thus, the mesh size of 250000 cells is seen to provide grid independent and accurate solution and is considered for further analysis since the flow parameters are independent of the mesh size. For evaluating convergence, residuals limits were set to a sufficient degree; lower than $10^{-6}$.

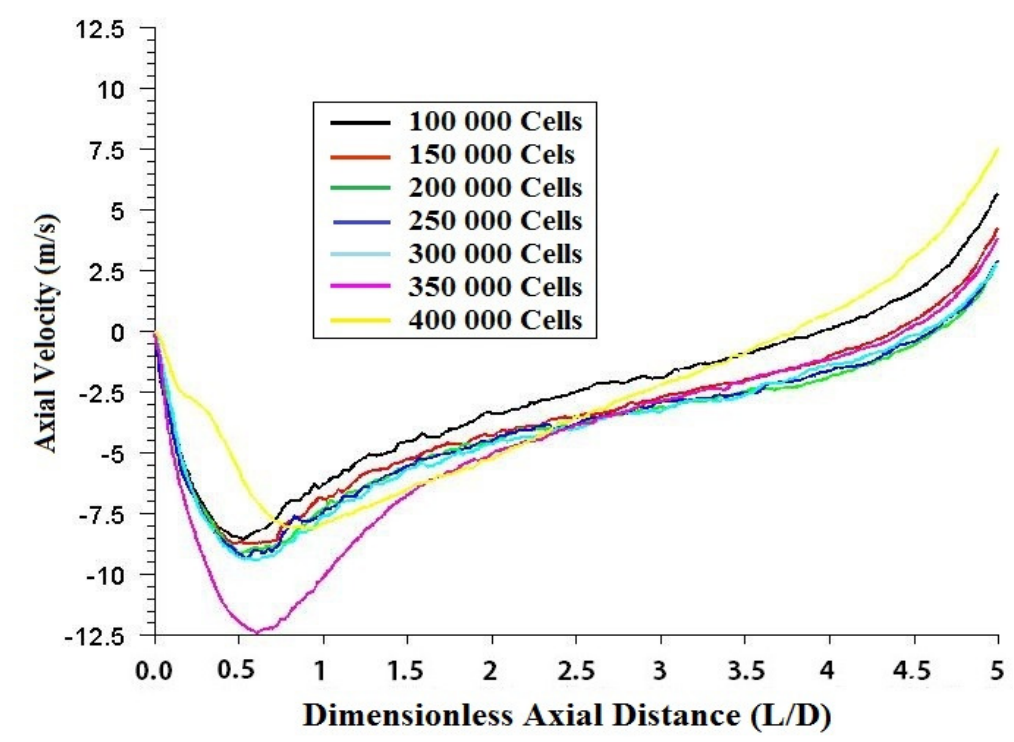

Fig. 2.Grid-independency study (Centerline Axial Velocity Distribution ). 


\section{Numerical Model Validation}

To validate the combustion model, the computational results were compared with the measured data. Calculations from the simulations are compared with the experimental data of Ref. [22]. Computational and experimental centerline temperature distributions at swirl number of $0.87, \mathrm{~A} / \mathrm{F}$ ratio of 30 are shown in Fig.3. The comparison shows a satisfactory agreement with maximum error of about $8 \%$. The temperature levels from computations are higher than that from experimental measurements. This is due to that the test combustor is cooled with water which absorbs quantitative amounts of heat and further heat is lost by convection and radiation [20]. Also, the use of a bare-wire thermocouple cooled by water with a junction does not obtain the same temperature of the combustion gases. Therefore, the measured temperature values are quite far from the calculated ones [21]. The solutions from these computational meshes were compared with experimental test data for the validation of the theoretical model solutions. Details of the experimental test rig are found in the experimental work performed in reference [22]. The combustor is tubular type of inner diameter and total length of 200 and $1000 \mathrm{~mm}$, respectively. The swirl number $(S=0.87)$ of the used air swirler and the air to fuel mass ratio $(\mathrm{A} / \mathrm{F}=30)$ with constant primary air flow rate are chosen and kept constant during the investigations.

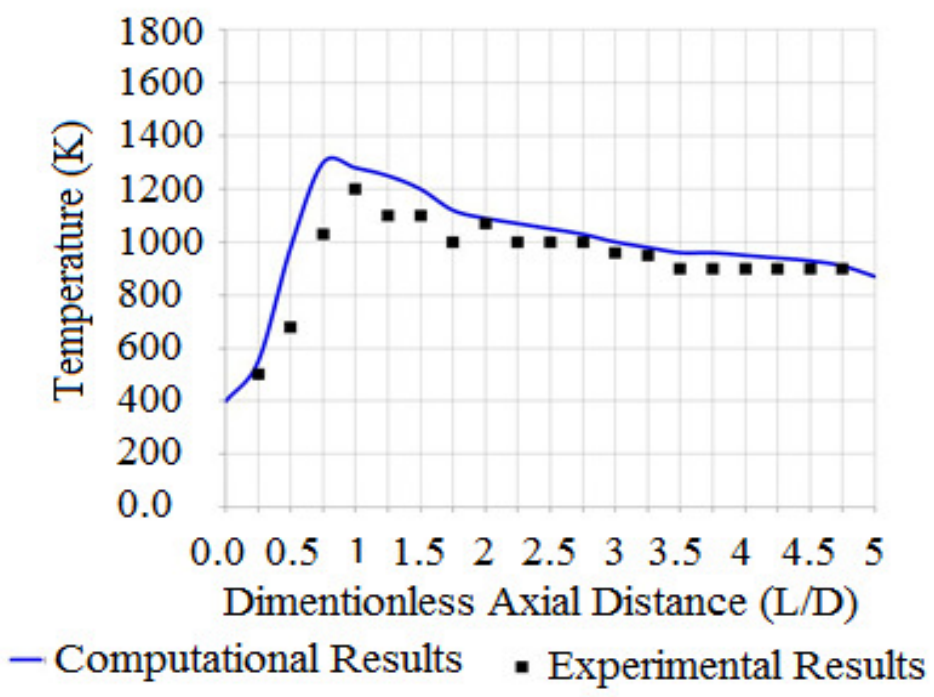

Fig. 3. Theoretical model validation.

\section{RESULTS AND DISCUSSION}

Previous studies showed that the favorable swirl blade angle fall around $45^{\circ}$ which leads to swirl number of 0.87 in the present swirl configuration. The effect of secondary air amount, inlet ports arrangements, inlet ports position and total numbers of ports on combustion and emissions is studied. Secondary air enters the combustor with different levels, different positions and different numbers of ports. First, the effect of $A / F$ ratio on temperature maps is investigated which has an obvious effect on flame size. This is to estimate the flame size with which secondary air can interact and achieve obvious effect of secondary air on the flame. 
The $A / F$ ratio takes the values of $20,25,30,35$ and 40 . During tests, the fuel flow rate is kept constant while the primary air flow rate is changed. Different ports arrangements of secondary air are considered. There are four, eight and sixteen levels of secondary air along the combustor length; the first level starts at $10 \%$ of the combustor length. The total number of inlet ports along the first half of the combustor varied from 16 to 256 ports. The effect of secondary air ports arrangement at constant $\mathrm{A} / \mathrm{F}$ ratio and constant swirl number and different (SPAR) on natural gas combustion characteristics is considered. Temperature maps, axial distributions of $\mathrm{CO}, \mathrm{CO}_{2}$, and $\mathrm{O}_{2}$ concentrations are determined and described.

\section{Effect of A/F Ratio}

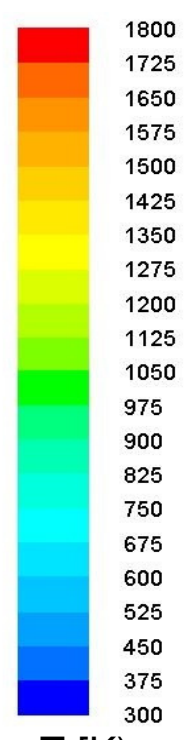

$\mathrm{T}[\mathrm{K})$

$$
\begin{aligned}
& A F=20 \\
& A F=25 \\
& A F=30 \\
& A F=35 \\
& A F=40
\end{aligned}
$$
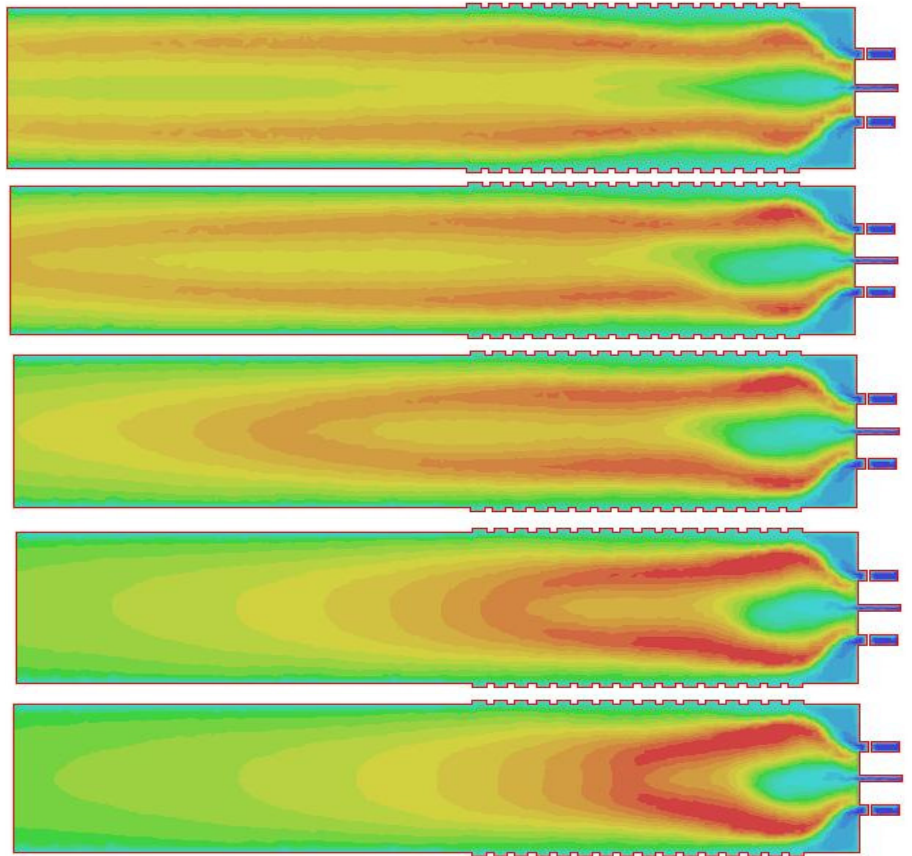

Fig. 4. Effect of $A / F$ ratio on temperature maps [SPAR=0 \& $S=0.87$ ].

The effect of $A / F$ ratio of on the temperature maps for $A / F$ ratios of $20,25,30,35$ and 40 is shown in Fig. 3.1. It is shown that for $A F=30$ the flame size nearly fills the combustor size. So, further studies were performed using this value of $A / F$.

For $A / F$ ratio of $20, \mathrm{~N}_{2} \mathrm{O}$ is out of range where the flme size is large and the flame temperature is very high poducing high $\mathrm{N}_{2} \mathrm{O}$ therefore $\mathrm{N}_{2} \mathrm{O}$ is not included here.

From Fig. 5, it is shown that as the $\mathrm{A} / \mathrm{F}$ ratio increases, the $\mathrm{NO}, \mathrm{N} 2 \mathrm{O}, \mathrm{CO}, \mathrm{CO}_{2}, \mathrm{O}_{2}$, soot concentrations and axial temperature distribution these all increase along the first part of the combustor centerline. Near the combustor end, $\mathrm{CO}, \mathrm{CO}_{2}$, soot, axial temperatures and radial temperatures have minimum values for the lower $A / F$ ratio. $\mathrm{N}_{2} \mathrm{O}$ has lower value for higher $\mathrm{A} / \mathrm{F}$ ratio. $\mathrm{CO}$ is decreased with increasing the $\mathrm{A} / \mathrm{F}$ ratio, at the second half of the combustor. $\mathrm{CO}_{2}$ decreased with increasing the value for $A / F$ ratio at the combustor end. From Fig. 5, it is also shown that the for the effect of $A / F$ ratio on soot volume fraction is nearly similar to that on $\mathrm{CO}$ and the trend of axial $\mathrm{CO} 2$ is similar to that of the axial temperature distributions. The minimum temperature at the combustor exit occurs when using higher $A / F$ ratio of 40. 

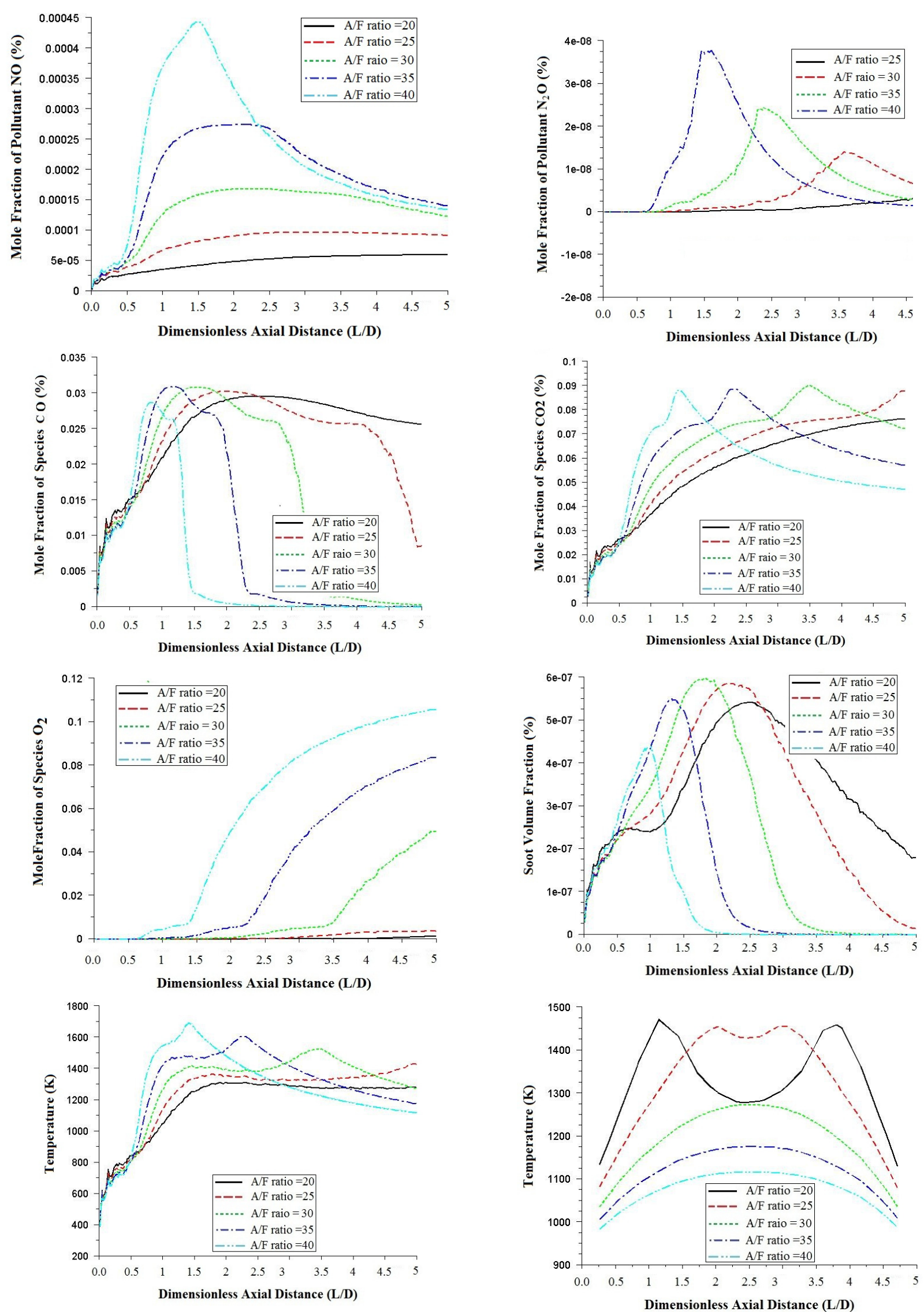

Fig. 5. Effect of $A / F$ on pollutants ( $N O$ and $N 2 O)$, exhaust species concentrations (CO, $C O 2, O 2)$, Soot, centerline temperature and radial temperature distribution at the combustor exit. 


\section{Effect of SPAR}

To clarify the effect of using secondary air on natural gas combustion, the first map drawn in each figure describes the temperature distribution without using the secondary air $(S P A R=0)$. A remarkable effect of using the secondary air on temperature maps is found. In the present study, it is focused on the effect of arrangement of secondary air inlet ports and the total number of ports on natural gas combustion. Therefore, the effect of secondary air on temperature maps was performed in two cases: $4 \times 4$ and 16×16 arrangements. In case of $4 \times 4$ arrangements, the flame is decreased in length and diameter with increasing the secondary as shown in Fig. 6. These results agree with that of Ibrahim et al. [19] and Gad et al. [6].

For $16 \times 16$ arrangement, the flame is slightly increased in length and slightly decreased in diameter with introducing secondary air. Then, with increasing the SPAR, the flame length is decreased again and the diameter also decreased as shown in Fig. 7, it is clear that as SPAR increased, the flame becomes narrow in diameter and its length is decreased slightly and the high temperature region sizes are united in one region and increased in size, Then the effect of secondary air on the temperature maps is differ due to the total number of secondary air ports.

Increasing the secondary air mass flow rate, at constant primary air flow rate, leads to increase its velocity and its momentum may press and compress the flame and then elongates the flame length, i.e. the flame is stretched and the secondary air entering from the upstream levels have more effect than that of the subsequent ports. For $4 \times 4$ arrangement, the secondary air seems to divide the flame because of its higher momentum, as shown from the temperature maps particularly at higher SPAR. From Figures 6,7 , it shown that, when increasing the total number of ports from $4 \times 4$ to $16 \times 16$ at same value of SPAR, the secondary air inlet velocity decreased and its momentum is also decreased, hence the sharing of the secondary air decreased and leads to decreasing in temperatures distribution.

Figures 8 and 9 show the effect of SPAR on: pollutants [NO\&N2O], exhaust species concentration ( $\mathrm{CO}, \mathrm{CO}_{2} \& \mathrm{O}_{2}$ ), Soot, centerline axial temperature, and radial temperature distribution at exit for $4 \times 4$ and $16 \times 16$ arrangements, respectively. The condition of SPAR $=0$ is included beside each curve to facilitate comparizon with other values of SPAR which take the values $0.30,0.60$ and 0.90 . Note, during the present study it is noticed that, for smaller flame sizes (ie, for $A / F$ ratio more than 30 , the effect of secondary air may be more clear because total $A / F$ ratio will be more effective this may need further studies in next paper. 


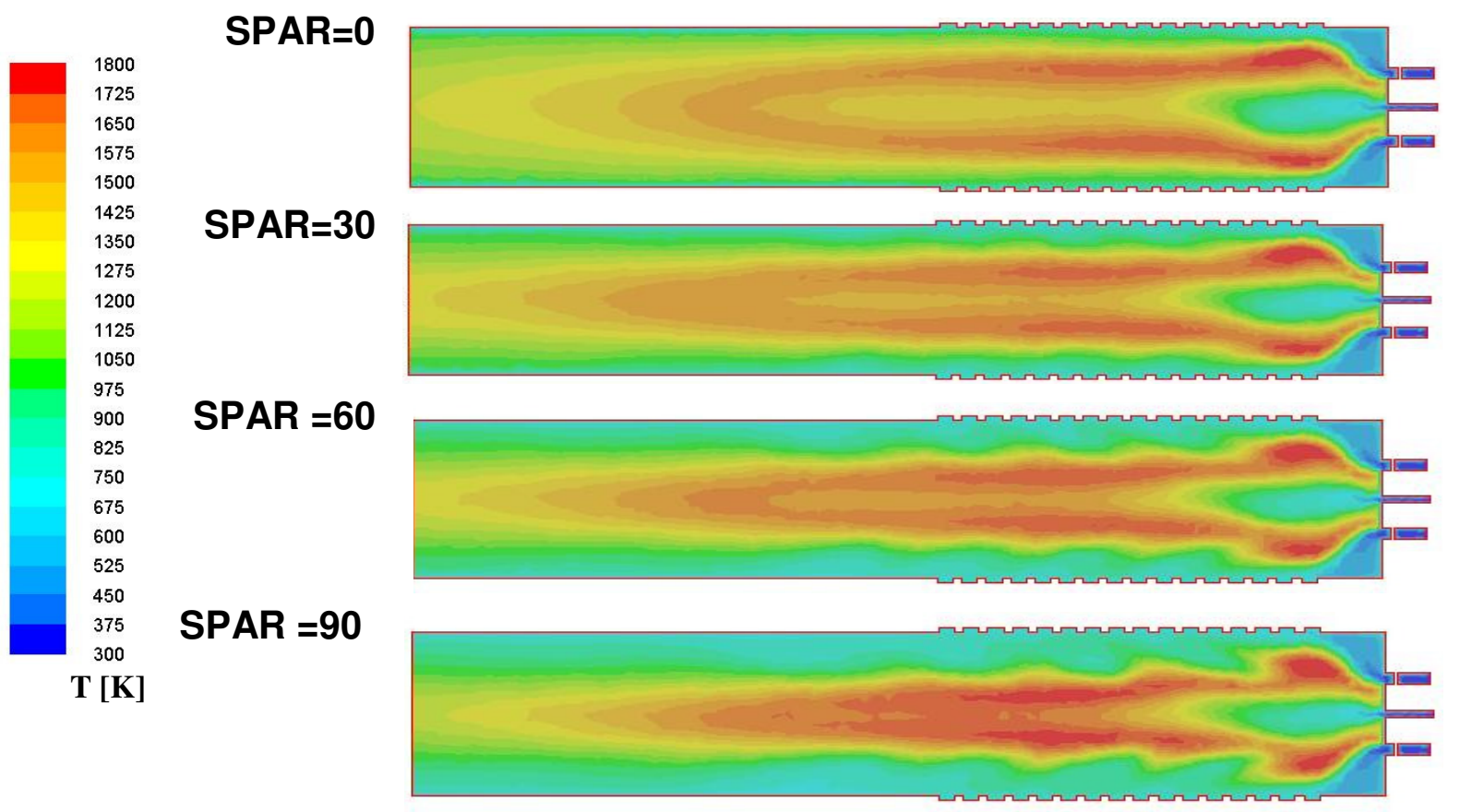

Fig. 6. Effect of SPAR on temperature maps for secondary ports arrangement of 4-4. $[A F=30]$.

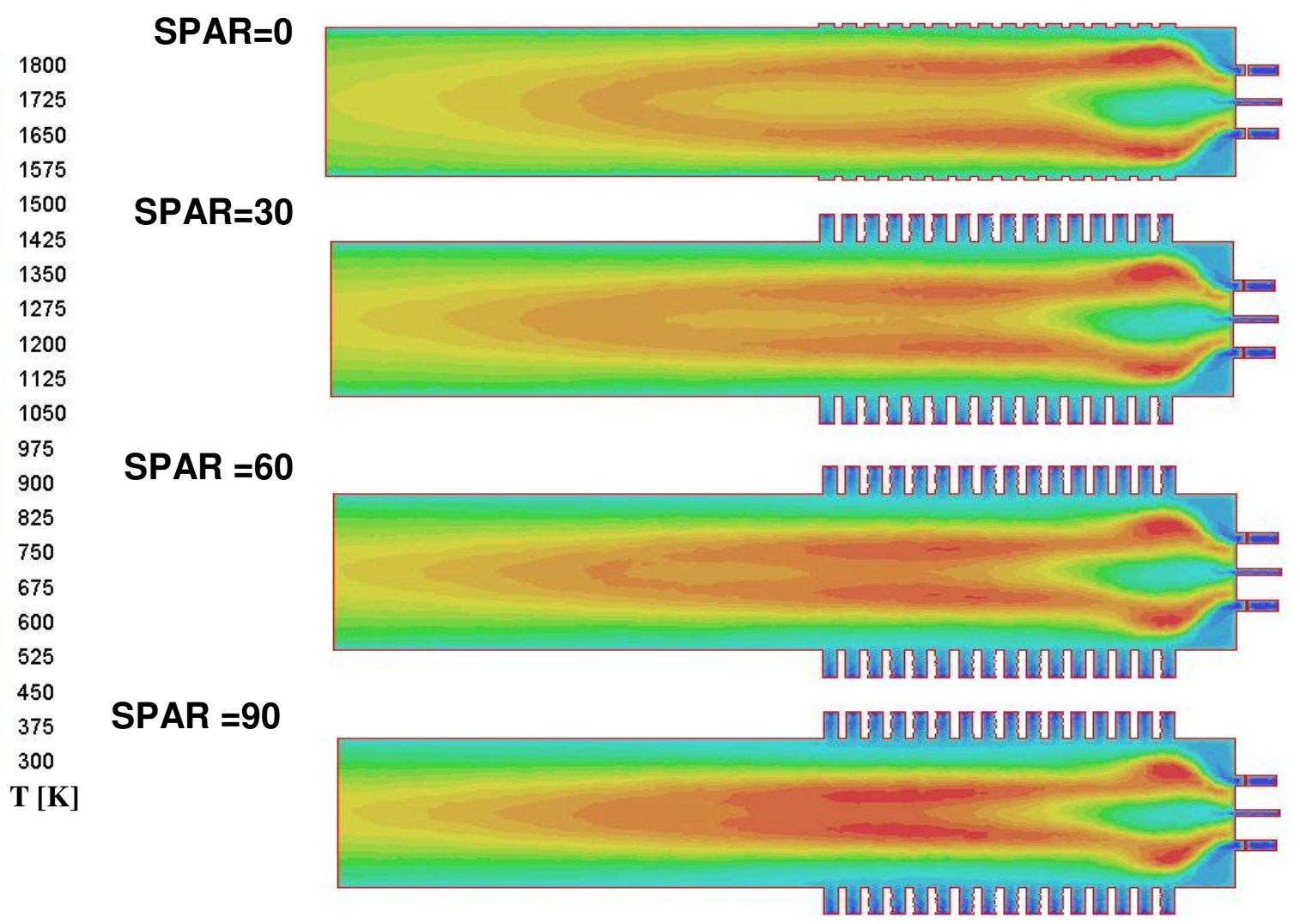

Fig. 7. Effect of SPAR on temperature maps for secondary ports arrangement of 16x16 $[A / F=30]$. 

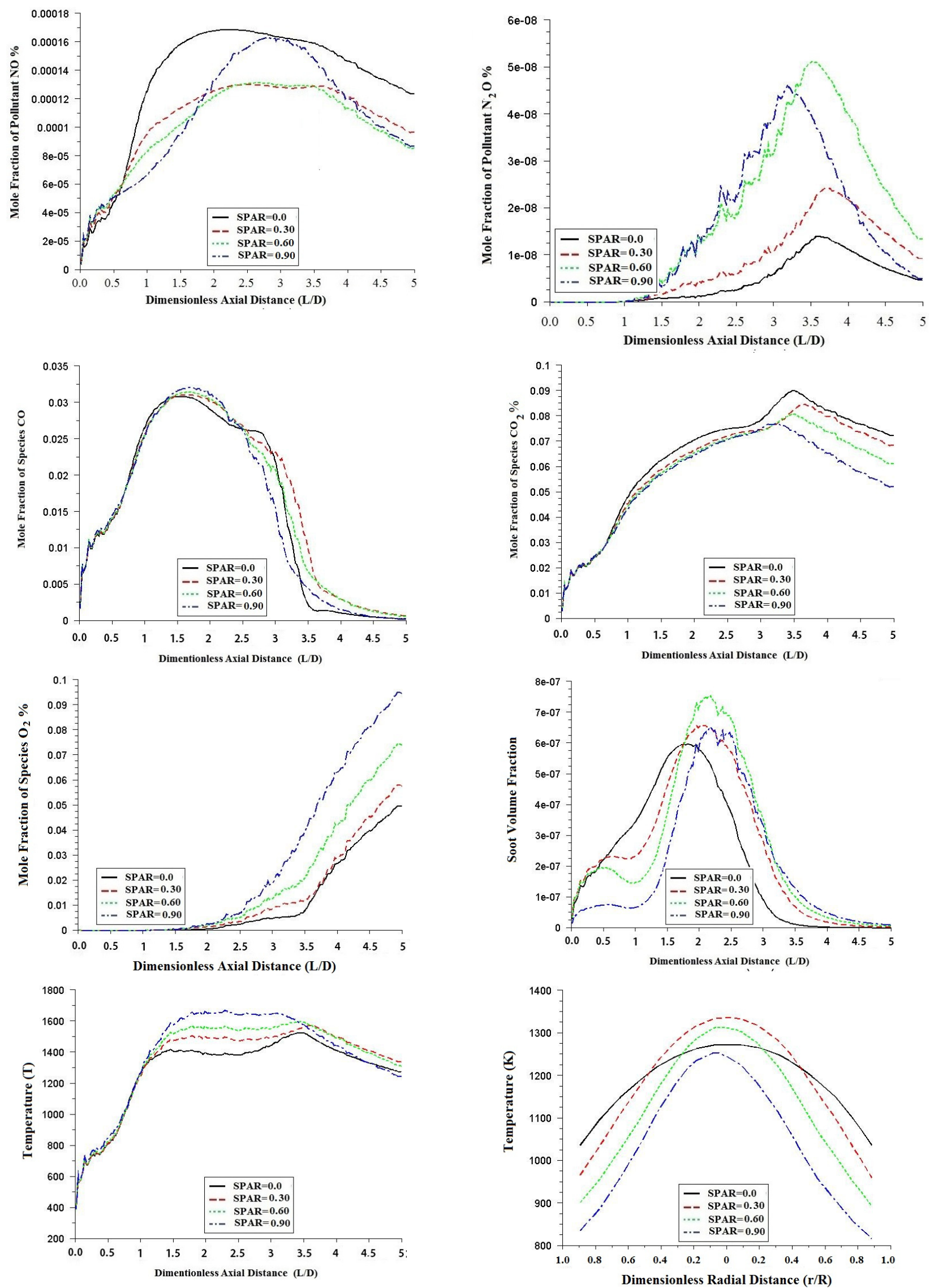

Fig. 8. Effect of SPAR on pollutants (NO\& N2O), species concentrations (CO, CO2, O2), Soot, centerline temperature and radial temperature distribution at the combustor exit [ $4 \times 4$ Arrangement]. 

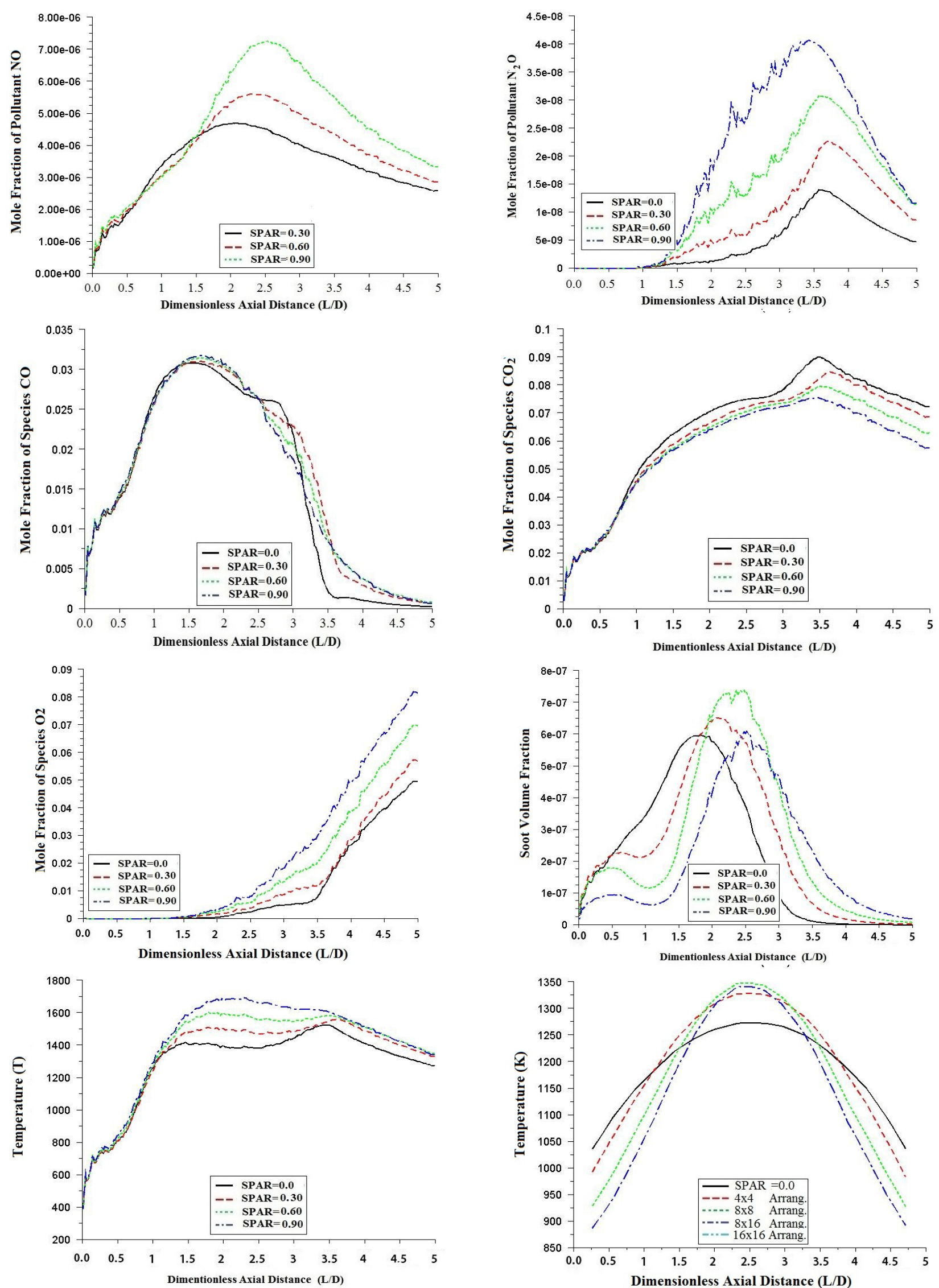

Fig. 9. Effect of SPAR on: pollutants [NO, N2O], exhaust species concentration (CO, $\mathrm{CO} 2, \mathrm{O} 2)$, Soot, centerline axial temperature, and radial temperature distribution at exit [16X16] arrangement. 


\section{Effect of Total Number of Ports}

It is convenient to investigate the effect of total number of inlet ports on combustion natural gas with air. In this section, the effects of the number of inlet ports on temperature maps, species concentrations and pollutant emissions are studied as shown in Fig. 10 and 11. Introducing secondary air from different number of ports affects the temperature distributions in the combustor and consequently the flame shape and length as shown in Fig. 10. The effect of secondary air arrangements having the total ports with different level group on the temperature, $\mathrm{CO}, \mathrm{CO}_{2}$, and $\mathrm{O}_{2}$ concentrations is shown in Fig.11, at same SPAR of $0.60, S=0.87$ and $A / F=30$.

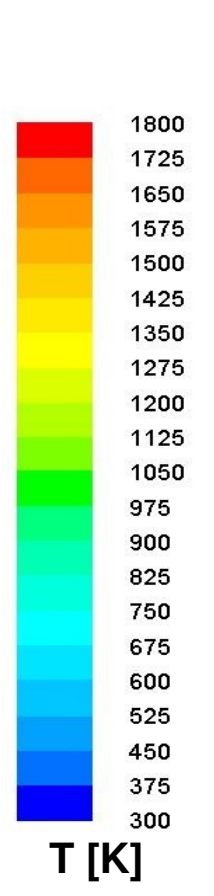

$$
\begin{aligned}
& \text { SPAR }=0 \\
& \text { Max temp. }=1890
\end{aligned}
$$

$4 X 16, A F=30$, Max temp. $=1860$

$8 \times 16, A F=30$,

Max temp. $=1860$

$4 \mathrm{X} 4, \mathrm{AF}=30$,

Max temp. $=1840$

$16 \times 16, A F=30$, Max temp. $=1850$

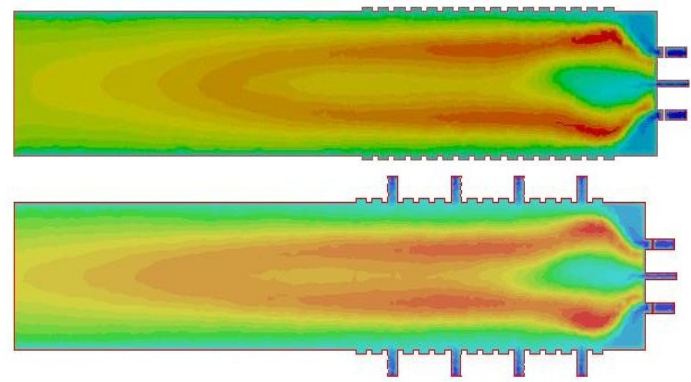

MIIMIMIR
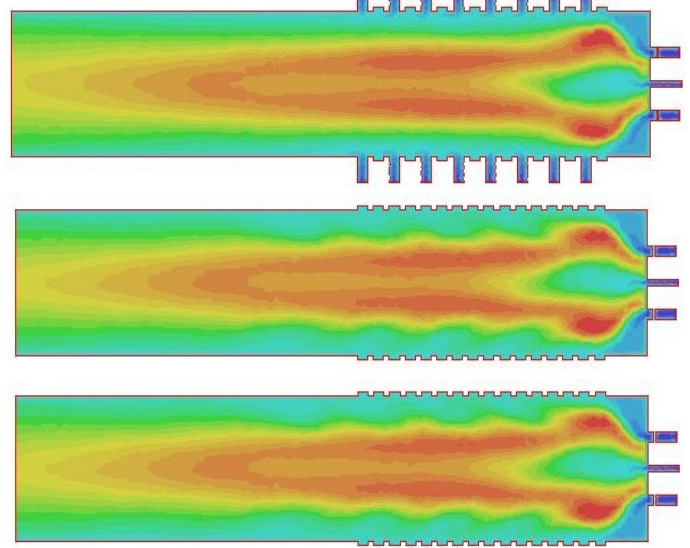

Fig. 10. Temperature maps for different numbers of $S A$ inlet ports $[A / F=30, S P A R=0.60$ [S $=0.87]$.

This analysis was performed under the same SPAR of 0.60 , AF ratio of 30 , and primary air swirl number of 0.87 as shown in figure 11. The effect of the first level of ports is more than of the other subsequent ports one. There is also a slight effect of the same total secondary air found on the flame length for SPAR more than 30 the flame is narrower in diameter.

The total numbers of inlet ports are selected for same secondary air inlet amount represented by SPAR $=0.60$, same A/F ratio of 30 and same swirl number of 0.87 . For16×16 arrangements, the flame length increases while flame diameter decreases. While for $4 \times 4$ the flame becomes narrow in diameter and shorter in length but for the diameter of the flame changes from upstream to downstream much smoother. As we changed from case to case the flame length decreased a little. The maximum temperature is mentioned below each case. Effect of total number of ports on radial temperature at exit is concluded from figures. For using the secondary air, the temperatures at the combustor centerline are higher than without using the 

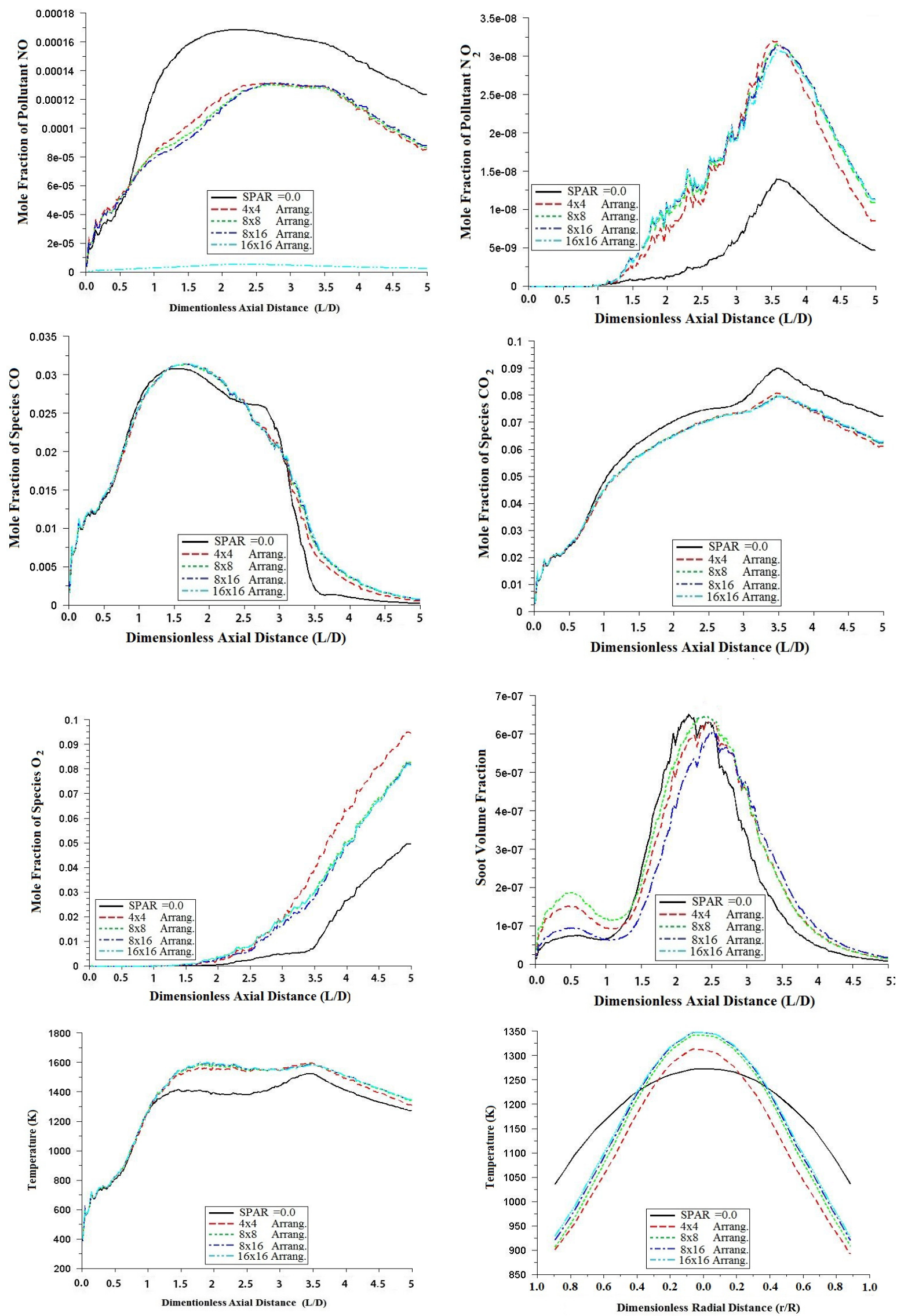

Fig.11. Effect of total number of ports on: pollutants [NO\&N2O], exhaust species (CO, CO2\&O2), Soot, axial temperature, and radial temperature distribution at exit $[S=0.87 \& A F=30, S P A R=60]$ 
secondary air. This is because the flame is longer in this case. For the cases with using the secondary air, at the combustor downstream end, the temperatures are lower with introducing the secondary air. For any ports number, the temperatures at combustor end are in case of using $16 \times 16$ and lower in case of using $4 \times 4$ ports arrangement.

\section{Effect of Secondary Air Inlet Ports Position}

We consider only the effect of position on temperature maps with considering the maximum temperature inside the combustor as shown in Fig. 12 and also the radial temperature at combustor exit because of its importance which affects greatly the turbine blades

\begin{tabular}{|c|c|}
\hline & $\begin{array}{l}\text { SPAR }=0 \\
\text { Max temn }=1890\end{array}$ \\
\hline $\begin{array}{l}1725 \\
1760\end{array}$ & \\
\hline $\begin{array}{l}1575 \\
1550\end{array}$ & 4x16 1st Quarter \\
\hline 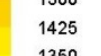 & Max temp. $=1865$ \\
\hline 1275 & \\
\hline 年1200 & \\
\hline & \\
\hline $\begin{array}{l}975 \\
900 \\
825\end{array}$ & $\begin{array}{l}4 \times 16 \text { 2nd Quarter } \\
\text { Max temo.=1875 }\end{array}$ \\
\hline $\begin{array}{l}770 \\
675 \\
600\end{array}$ & \\
\hline $\begin{array}{l}525 \\
450\end{array}$ & \\
\hline $\begin{array}{l}375 \\
370\end{array}$ & $4 \times 16$ 1st Half $[50 \mathrm{~cm}]$ \\
\hline $\mathrm{T}[\mathrm{K}]$ & Max temp.=1863 \\
\hline
\end{tabular}

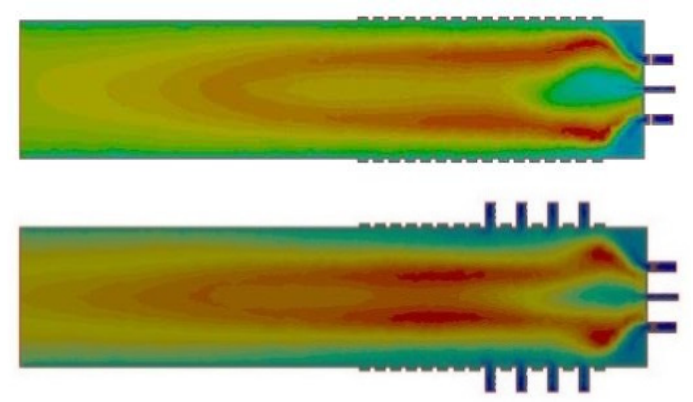

IMI

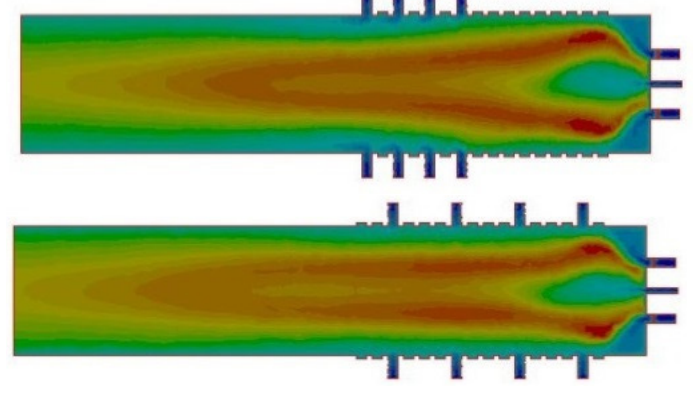

Fig.12. Temperature maps for different numbers of $S A$ inlet ports $[A / F=30, S P A R$ $=0.60[S=0.87]$.

\section{CONCLUSIONS}

The effect of secondary air ports arrangement on the natural gas combustion with air is studied numerically by using the non-premixed combustion model, two step soot model and NOx model. These three-dimensional models were used to simulate the turbulent reacting flow in the computational fluid dynamics package ANSYS Fluent 12. Secondary air was introduced normally in the model combustor through its first half. The effect of using secondary air with different amounts, different inlet ports number, positions and arrangements were investigated. Four, eight and sixteen levels, each with four, eight or sixteen ports in each level are used. Thus, the total number of ports varied from 16 up to 256 . The air swirl number and the air to fuel ratio are kept constant for all runs, which take the values 0.87 and 30 , respectively. From the numerical investigation, following conclusions are obtained:

1- As a general conclusions secondary air amounts, ports arrangement, ports density and their position affect the following: temperature maps, pollutant emissions such as $\mathrm{NO}$ and $\mathrm{N}_{2} \mathrm{O}$, exhaust species concentrations such as $\mathrm{CO}$, 
$\mathrm{CO}_{2}, \mathrm{O}_{2}$, Soot concentrations, and centerline and radial temperature distribution at the combustor exit.

2- The secondary air has a significant effect on the temperature maps. The flame becomes narrow and shorter for secondary to primary air ratio (SPAR) over 0.30 .

3- For SPAR $=0.90$, the flame size was decreased in its length and diameter by about $25 \%$ and $20 \%$ for secondary air ports arrangement of $4-4$ and $16 \times 16$, respectively.

4- As the secondary air ports density increased, the flame diameter becomes narrower while the flame length decreased a little.

5- The secondary air tends to divide the flame from its first lower part as concluded from the temperature maps particularly for 4-4 ports arrangement at high levels of secondary to primary air ratio.

6- The secondary air when enter the combustor from higher ports density compresses the flame and force it to be narrow in diameter and slightly longer in length.

7- The centerline concentrations of $\mathrm{CO}_{2}, \mathrm{CO}$ and $\mathrm{O}_{2}$ are similar to that of temperatures maps.

\section{REFERENCES}

[1] N. Syred, and J. M. Beer, "Combustion in Swirling Flow: A Review", Combustion and Flame, 1974, 23:143-201.

[2] N. Syred, T. O'Doherty, and D. Froud, "The Interaction of the Precessing Vortex Core and Reverse Flow Zone in the Exhaust of a Swirl Burner", Journal of Power and Energy, 1994, 208: 27-36.

[3] A. Ibrahim, "Effect of Secondary Air on the Flow Field Inside a Gas Turbine Combustor", Port Said Research Journal, Faculty of Engineering-Port Said University, Vol. 16, No. 1.

[4] Y. A. Eldrainy, J.M.M. Ridzwan, and M.N.M. Jaafar, "Prediction of the flow inside a micro gas turbine combustor", Journal of Mechanical, 2008, 25: 5063.

[5] H. M. Gad, T.M. Farag, S.I. Abdel-Mageed, S.E. Habik. and A.H. EzzEldien "Kerosene Spray Combustion Characteristics in a Swirl Type Combustor with Normal Secondary Air", Port Said Engineering Research Journal, 2010, 14, (2): $52-66$.

[6] Mingyan Gu, Mingchuan, Weidong Fan, Lei Wang and Fengguo Tian, "The effect of the mixing characteristics of primary and secondary air on $\mathrm{NO}_{x}$ formation in a swirling pulverized coal flame", Fuel 84 (2005) 2093-2101.

[7] H.M. Gad, A. Ibrahim, A. K. Abd El-Samed, T.M. and Farag, "Effect of Secondary Air Inlet Ports Arrangement on N.G. Flame Combustion Characteristics", Port Said Engineering Research Journal, Faculty of Engineering - Port Said University, Volume 17 No. 2 pp.1-15

[8] T.M. Farag, "A Study on the Flow Field and Spray Combustion Characteristics in a Swirl Type Combustor", Ph.D. Dissertation, 1983, Department of Mechanical Engineering, Hiroshima University.

[9] H.M. Gad, T.M. Farag, S.I. Abdel-Mageed, S.E. Habik and A.H. EzzEldien,"Effect of Secondary Air Direction on the Kerosene Spray Combustion Characteristics", Port-Said Engineering Research Journal, Volume 14, No. 2, September 2010, pp. 41-51. 
[10] J. Jing, Z. Li, Q. Zhu, Z. Chen and F. Ren, "Influence of primary air ratio on flow and combustion characteristics and NO Emissions of a new swirl coal burner", Energy, 2011, 36: 1206-1213.

[11] H.S. Zhen, C.W. Leung, and C.S. Cheung, "Thermal and emission characteristics of a turbulent swirling inverse diffusion flame", Int. Journal of Heat and Mass Transfer, 2010, 53: 902-909.

[12] I.K. Nam, M.Y. Young, and J.L. Min, "Non-premixed flame characteristics of opposed methane jets in coaxial narrow air stream tubes", International Journal of Heat and Fluid Flow, 2010, 31: 680-688.

[13] S.N. Singh, V. Seshadri, R.K. Singh, and T. Mishra, "Flow Characteristics of an Annular Gas Turbine Combustor Model for Reacting Flows Using CFD", Journal of Scientific and Industrial Research, 2006, 65: 921-934.

[14] A.K. Abdel-Samed, "Natural Gas Flame Characteristics and Emissions", PortSaid Engineering Research Journal, Vol.14, No.1, pp.137-152, March 2010.

[15] A.B. Lebedev, A.N. Secundov, A.M. Starik, N.S. Titova, and A.M. Schepin, "Modeling study of gas-turbine combustor emissions" proceeding of the combustion institute, 2009, 32: 2942947.

[16] F. Mare, W.P. Jones, and K.R. Menzies, "Large eddy simulation of a model gas turbine combustor", Combustion and Flame, 2004, 137: 278-294.

[17] J. Zhang, Y. Pu, and L. Zhou, "Turbulence Characteristics of Swirling Reacting Flow in a Combustor with Staged Air Injection" Chinese J. Chem. Eng., 2006, 14 (5): 634-641.

[18] M. Shehata, "Emissions and wall temperatures for lean pre-vaporized premixed gas turbine combustor" Fuel, 2009, 88: 446- 455

[19] A. Ibrahim, Nasser Shelila , A.H. EZZ El-Dien, M. Moslehb and T.M. Farag, "Experimental and Theoretical Study of the Effect of Secondary Air Direction on Natural Gas Diffusion Flame", PSERJ, Vol. No.2, 2011.

[20] T.M. Farag, " A study of atomized premixed flame structure", M. Sc. thesis, Cairo university 1977.

[21] Fawzy El-Mahallawy and Saad El-Din Habic "Fundamental and technology of combustion", Sevier Science Ltd First edition 2002.

[22] Ahmed Farag, "A study of secondary air effect on natural gas combustion characteristics", Ph.D. Dissertation, 2012, Port Said University, Egypt. 